\title{
Desafios Enfrentados no Manejo da Tuberculose Pulmonar em Unidade de Saúde da Família: um Relato de Experiência
}

\author{
Fernandes, Marcelo Henrique Ferreira; Cavalcanti, Luiz Rafael Pereira; \\ Carvalho, David Ramos de \\ Universidade Federal de Pernambuco — fernandeshfmarcelo@gmail.com
}

Introdução: a tuberculose pulmonar é uma doença infectocontagiosa de transmissão por via aérea que, segundo a Organização Mundial de Saúde (OMS), infecta cerca 02 bilhões de pessoas ao redor do mundo. É a principal causa de morte por doença infecciosa em adultos nos países em desenvolvimento, representando um grave problema de saúde pública, devido, principalmente, a não aderência ao tratamento, ao diagnóstico tardio e subdiagnóstico e ao não controle de contatos, o que faz com que a população continue susceptível à infecção, estigmatizando-a como uma doença negligenciada. Objetivos: Descrever a experiência, como internos da graduação do curso de Medicina, em uma Unidade de Saúde da Família (USF) na elaboração de um projeto de rastreio de sintomáticos respiratórios de uma determinada comunidade. Segundo o Ministério da Saúde, espera-se que $1 \%$ da população seja sintomática respiratória e que, destes, $4 \%$ sejam bacilíferos. Tem-se o intuito de avaliar este espaço amostral de pacientes com algum sintoma respiratório e classificá-lo, quando possível. Métodos: Traçou-se um mapa de pacientes que constavam com algum sintoma respiratório relevante e, a partir dos pontos mais densamente habitados por estes, começou-se uma busca ativa por mais, possíveis, sintomáticos respiratórios, visitando casa a casa e conscientizando a população sobre as manifestações iniciais e a importância de procurar o posto de saúde para a pesquisa por via de baciloscopia de escarro. na unidade de saúde, foram realizadas palestras na sala de espera acerca do tema, elaborou-se o "Dia da Tosse" e os pacientes foram encorajados a trazer seus familiares e conhecidos com alguma suspeita para a triagem. Resultados: Percebe-se que tanto os pacientes portadores do bacilo de Koch, quanto os que possuíam algum sintoma pertinente eram subnotificados, diminuindo a cobertura que a USF poderia realizar. em relação aos que eram notificados, notamos algumas falhas no preenchimento e atualização dos registros, prejudicando o seguimento e prevenção dos pacientes. Notamos, contudo, um aumento do número de pessoas que procuraram o posto visando esclarecer dúvidas acerca de seus sintomas respiratórios, seja para realizar a baciloscopia ou apenas adquirir mais conhecimento sobre o tema. Conclusões: Diversos problemas influenciam o diagnóstico, o tratamento e o seguimento dos pacientes portadores e seus contatos: desde problemas como a notificação, o armazenamento e a atualização de dados até o relativo desinteresse da população em procurar a USF quando frente a sinais e sintomas, neste caso, respiratórios. Concluí-se que a busca ativa por tais pacientes, a educação dos moradores sobre a doença e seus sinais de alerta e a conscientização dos profissionais de saúde acerca de um correto registro das informações são pontos fundamentais para uma melhor cobertura do posto no que diz respeito à estratificação e ao tratamento de pacientes potencialmente infectados.

Fernandes, Marcelo Henrique Ferreira; Cavalcanti, Luiz Rafael Pereira; Carvalho, David Ramos de. Desafios Enfrentados no Manejo da Tuberculose Pulmonar em Unidade de Saúde da Família: um Relato de Experiência.. In: Anais do Congresso Internacional de Humanidades \& Humanização em Saúde [= Blucher Medical Proceedings, num.2, vol.1]. São Paulo: Editora Blucher, 2014. ISSN 2357-7282

DOI 10.5151/medpro-cihhs-10846 